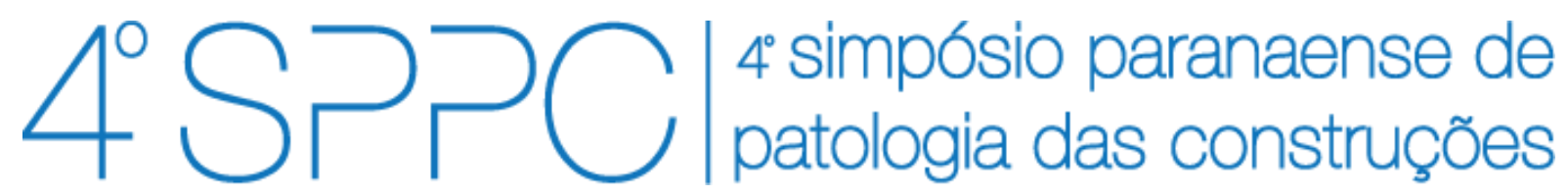

ISSN 2526-7248 artigo n. 4SPPC133, pp. 312-320, 2019

\title{
Comportamento de vigas de concreto reforçadas com aço e com barras de fibra de basalto
}

\author{
Baldessar, Gean Marcos Warmling'; Santos Filho, Mauro Lacerda 2; Dalledone, \\ Roberto Machado ${ }^{3}$; Pieralisi, Ricardo ${ }^{4}$ \\ ${ }^{1}$ Mestrando PPGECC, Universidade Federal do Paraná, bwgean@gmail.com \\ 2 Professor, Universidade Federal do Paraná, mauro.lacerda@ufpr.br \\ ${ }^{3}$ Professor, Universidade Federal do Paraná, rdm@ufpr.br \\ ${ }^{4}$ Professor, Universidade Federal do Paraná, ricpieralisi@ufpr.br
}

\begin{abstract}
Resumo: As barras de aço comumente utilizadas na construção civil são suscetíveis à corrosão, sobretudo quando sujeitas à ambientes agressivos. Materiais constituídos por polímeros podem ser uma alternativa viável para substituição do aço nesses casos. Compósitos em fibra de basalto são um material relativamente novo e sua aplicação estrutural está iniciando no Brasil na forma de barras. Com intutito de conhecer melhor o comportamento desse material foram moldadas quatro vigas, duas reforçadas com barras de aço e duas com barras em fibra de basalto. As vigas foram submetidas à ensaios de flexão onde puderam ser observados os modos de ruptura e as relações carga-deflexão. Devido à limitações dos ensaios o esforço de cisalhamento foi preponderante na ruptura das vigas. As vigas dos dois materiais apresentaram uma carga última muito próxima e maiores deflexões foram verificadas na viga reforçada com fibra de basalto.
\end{abstract}

Palavras-chave: fibra de basalto, concreto reforçado com polímeros, materiais compósitos

Abstract: Steel bars used in civil construction are a material prone to corrosion, especially if subjected to aggressive environment. Polymeric materials can be a viable alternative to replace steel in this case. Basalt fiber polymer is a relatively new material, and its structural application begins in Brazil in the form of bars. In order to better understand the material behavior, four beams were cast, two reinforced with steel bars and two with basalt fiber bars. The beams were submitted in a 3-points bending test to observe the failure characteristics and the load-deflection relation. Due to test restrictions, shear prevailed in the failure mode. The beams of the two materials resisted almost the same load, but greater deflections were verified in the beams reinforced with basalt fiber.

Keywords: basalt fiber, fiber-reinforced polymer concrete, composite materials 


\section{Introdução}

No projeto de uma estrutura um dos aspectos mais importantes a ser observado é a durabilidade da mesma. As estruturas convencionais de concreto armado são duráveis pois o aço é protegido contra a corrosão através de um filme passivo formado na sua superfície. Esse filme é decorrência do ambiente altamente alcalino provido pelo concreto ao redor da barra [1]. Contudo, processos construtivos inadequados, desconhecimento das condições de serviço e ausência de manutenção adequada podem fazer com que íons cloreto penetrem no concreto, ocasionando a destruição do filme de proteção e iniciando o processo corrosivo. A corrosão devido ao ataque por cloretos é uma das causas mais graves de degradação das estruturas de concreto armado [2]. De acordo com um estudo elaborado em 2016, estimou-se em US $\$ 2,5$ trilhões o custo global decorrente da corrosão [3].

A maioria dos polímeros, ao contrário do aço, apresentam propriedades como resistência à corrosão e neutralidade eletromagnética, e podem ser utilizados em locais onde o aço não é adequado devido aos problemas relacionados com a durabilidade, como por exemplo ambientes com elevado teor de cloretos. Alguns estudos, como por exemplo o realizado em [4], mostraram que polímeros não sofreram degradação em concretos que utilizam água e areia do mar.

O uso de concreto reforçado com barras de polímeros em substituição ao aço vem crescendo nas últimas décadas devido, além de ser inerte à corrosão, ao baixo peso próprio e elevada tensão de ruptura. Inúmeros estudos abordaram a efetividade da utilização de concreto reforçado com barras de polímeros. Contudo, os materiais são geralmente caracterizados por possuir um baixo módulo de elasticidade, quando comparado com os aços, e uma resposta elástica linear até a ruptura [5]. Atualmente as fibras mais conhecidas e utilizadas comercialmente como reforço no concreto são as fibras de vidro e de carbono.

As fibras de vidro apresentam baixo módulo de elasticidade, elevada resistência à tração, baixa resistância ao cisalhamento e comportamento elástico-linear até a ruptura. Isso faz com que com que as deflexões e fissuras numa viga reforçada com fibra de vidro sejam maiores que as vigas comuns reforçadas com aço. Devido à esse comportamento, o cálculo de vigas utilizando fibra de vidro é feito com base no Estado Limite de Serviço [6].

As fibras de carbono apresentam, por sua vez, um desempenho melhor que as fibras de vidro, com um módulo de elasticidade próximo ao do aço, porém com um custo muito elevado. Por isso, são utilizadas comercialmente apenas como reforço em obras que necessitam de aumento da capacidade de carga ou que tenham algum impedimento ou dificuldade de reforço convencional.

Já as fibras de basalto, produzidas a partir do derretimento da rocha vulcânica, tem ganhado espaço nos últimos anos sobretudo pelas boas propriedades de resistência, rigidez, durabilidade, resistência à ácidos e solventes e baixa absorção de água. Além disso, o processo de fabricação é mais barato que o das fibras de vidro e de carbono [7]. Em relação às propriedades mecânicas, as fibras de basalto possuem desempenho superior às fibras de vidro e inferior em relação às fibras de carbono [8]. 
As fibras de basalto, quando comparadas com as fibras de vidro e de carbono, podem ser utilizadas com o intuito de melhorar a segurança e a confiabilidade das estruturas. Contudo, por se tratar de uma tecnologia relativamente recente, estudos básicos e aplicações relevantes ainda são limitados. Além disso, as atuais normativas para dimensionamento de concreto reforçado com polímeros ainda não contemplam a utilização de fibras de basalto [9].

O objetivo do presente estudo é avaliar a possibilidade da substituição da armadura convencional em aço por barras de fibras de basalto em ambientes agressivos. Para isso verificou-se o comportamento de vigas com armadura longitudinal e transversal composta somente por barras de fibra de basalto com vigas compostas por armadura em aço comum. Para tanto foram moldadas seis vigas, três com barras feitas a partir fibra de basalto e três com armadura em aço (vigas referência). As vigas foram rompidas na condição biapoiada com uma carga aplicada no meio do vão.

\section{Programa experimental}

Os ensaios das vigas à flexão foram executados no LAME- Laboratório de Materiais e Estruturas, da Universidade Federal do Paraná utilizando a máquina universal de ensaios ZD-100, com capacidade de $1000 \mathrm{kN}$.

A utilização desse equipamento limitou o comprimento da viga, o que levou a um comportamento estrutural em que o esforço de cisalhamento foi preponderante em relação à flexão. Assim sendo, os ensaios puderam confirmar qualitativamente se há similaridade no comportamento estrutural entre as vigas com reforço em fibra de basalto e as vigas de referência.

\subsection{Características das vigas}

A Figura 1 ilustra a disposição do reforço utilizado nas vigas de $100 \mathrm{~cm}$ de comprimento e seção transversal retangular de $10 \times 20 \mathrm{~cm}$. A armadura utilizada é constituída por duas barras com diâmetro de $5 \mathrm{~mm}$ na armadura superior, $8 \mathrm{~mm}$ na armadura inferior, estribos com diâmetro de $4,2 \mathrm{~mm}$ espaçados a cada $15 \mathrm{~cm}$. O cobrimento adotado foi de $1,5 \mathrm{~cm}$. Utilizou-se a mesma configuração para as vigas reforçadas com aço e com fibra de basalto.
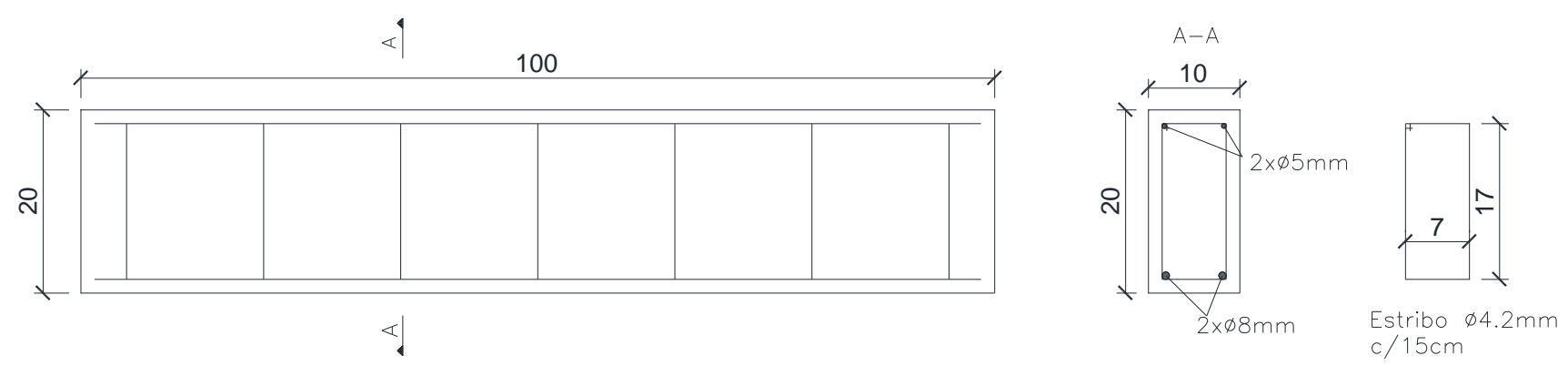

Figura 1: Geometria e disposição do reforço nas vigas ensaiadas 
O concreto utilizado possuía uma resistência característica aos 28 dias de $20 \mathrm{MPa}$. aço, de acordo com o fabricante possui uma resistência ao escoamento de $500 \mathrm{MPa}$ e módulo de elasticidade de $210 \mathrm{GPa}$. As barras em fibra de basalto, também de acordo com o fabricante, possuem uma resistência última de $800 \mathrm{MPa}$ (sem patamar de escoamento) e módulo de elasticidade de 50 GPa.

\subsection{Ensaio de flexão de 3 pontos}

As vigas foram ensaidas à flexão na condição biapoiada com uma carga centrada (ensaio de flexão de 3 pontos), como pode ser observado na Figura 2. Durante o ensaio foram medidas as deflexões com a utilização de um defletômetro (Figura 3), os dados foram constantemente registrados e armazenados.

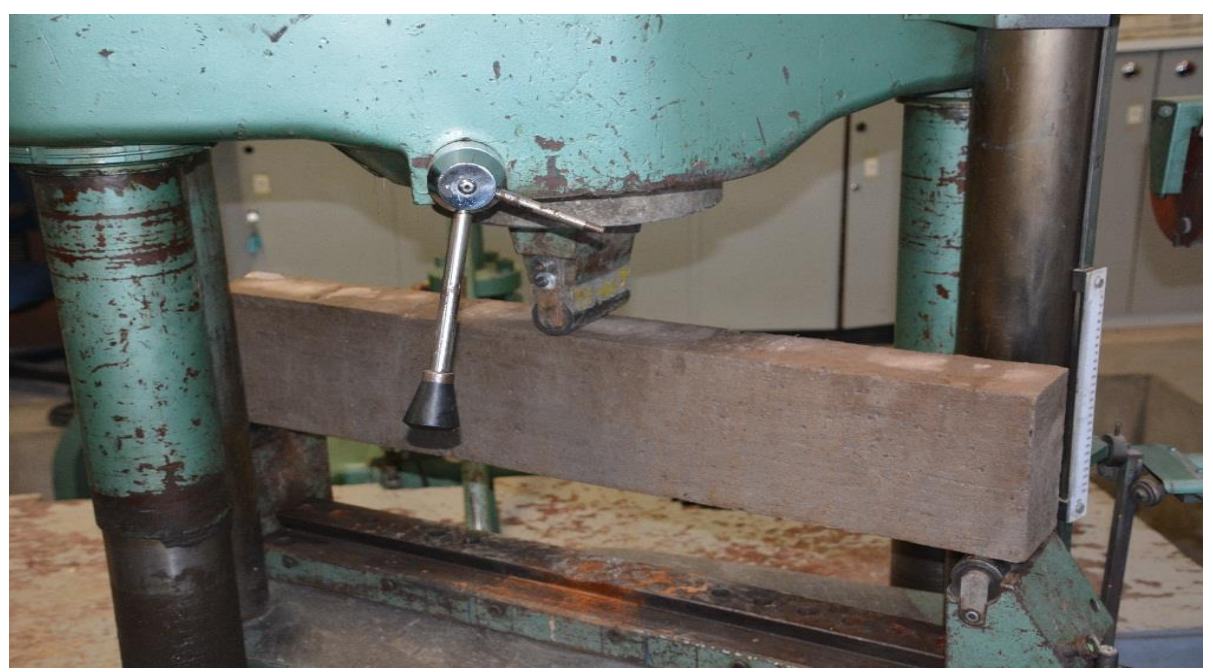

Figura 2: Esquema do ensaio

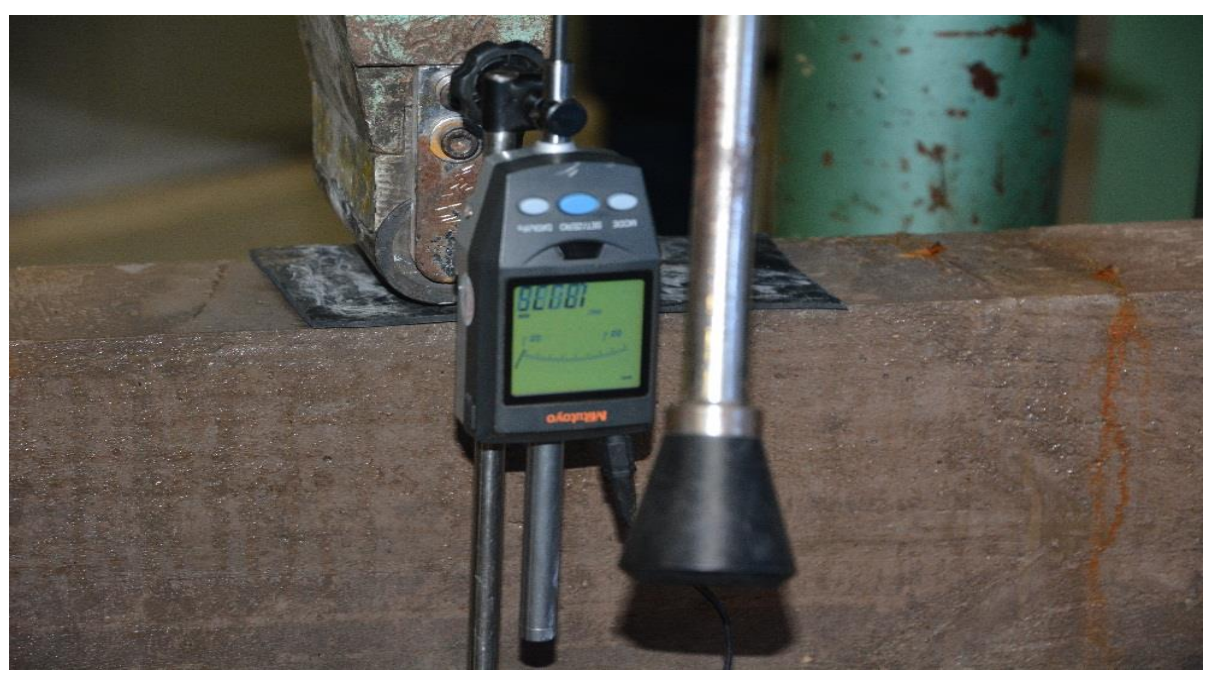

Figura 3: Detalhe do defletômetro 


\section{Resultados}

\subsection{Modos de ruptura}

Em virtude da limitação de tamanho de elementos estruturais que a prensa utilizada pode ensaiar, a relação altura/comprimento das vigas fabricadas é de 0,2 . Devido a esse elevado valor, as vigas apresentaram um comportamento em que o esforço de cisalhamento foi preponderante na ruptura.

A primeira viga de concreto reforçada com aço apresentou ruptura por cisalhamento, observando-se inclusive a ruptura de um dos estribos junto à face inferior. $O$ detalhe da ruptura do estribo é mostrado na Figura 4.

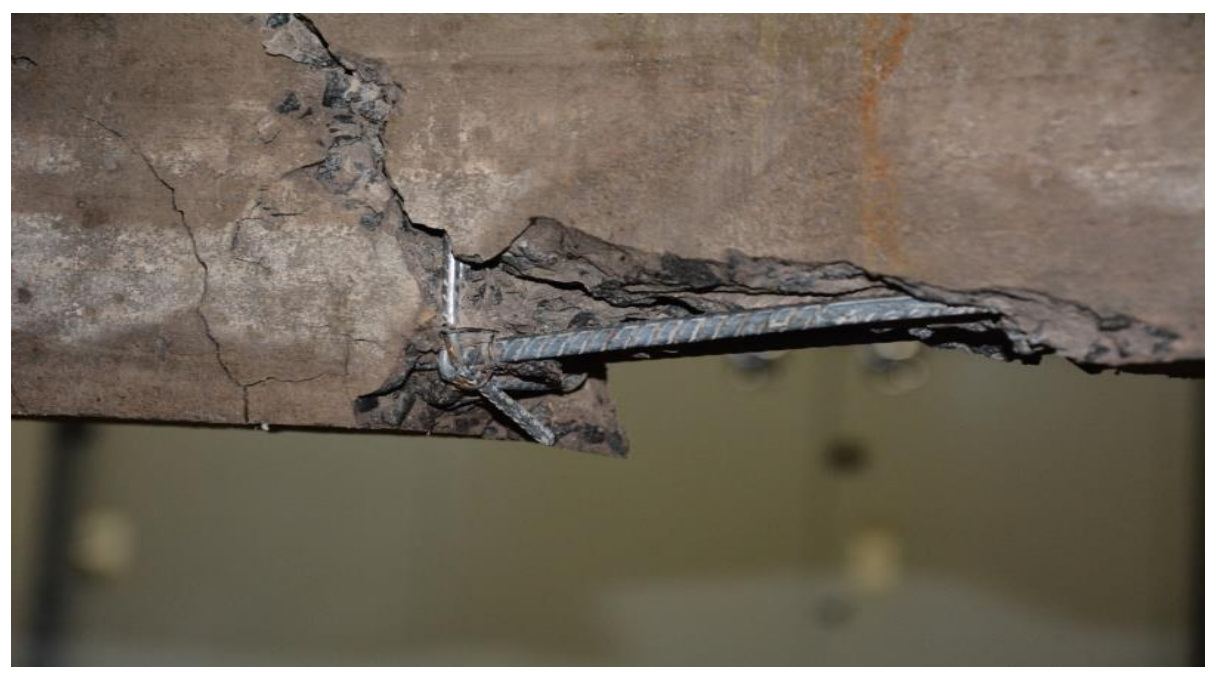

Figura 4: Ruptura do estribo na viga reforçada com aço

Por outro lado, a segunda viga de concreto armado rompeu por esmagamento do concreto na face superior, a foto da segunda viga é apresentada na Figura 5.

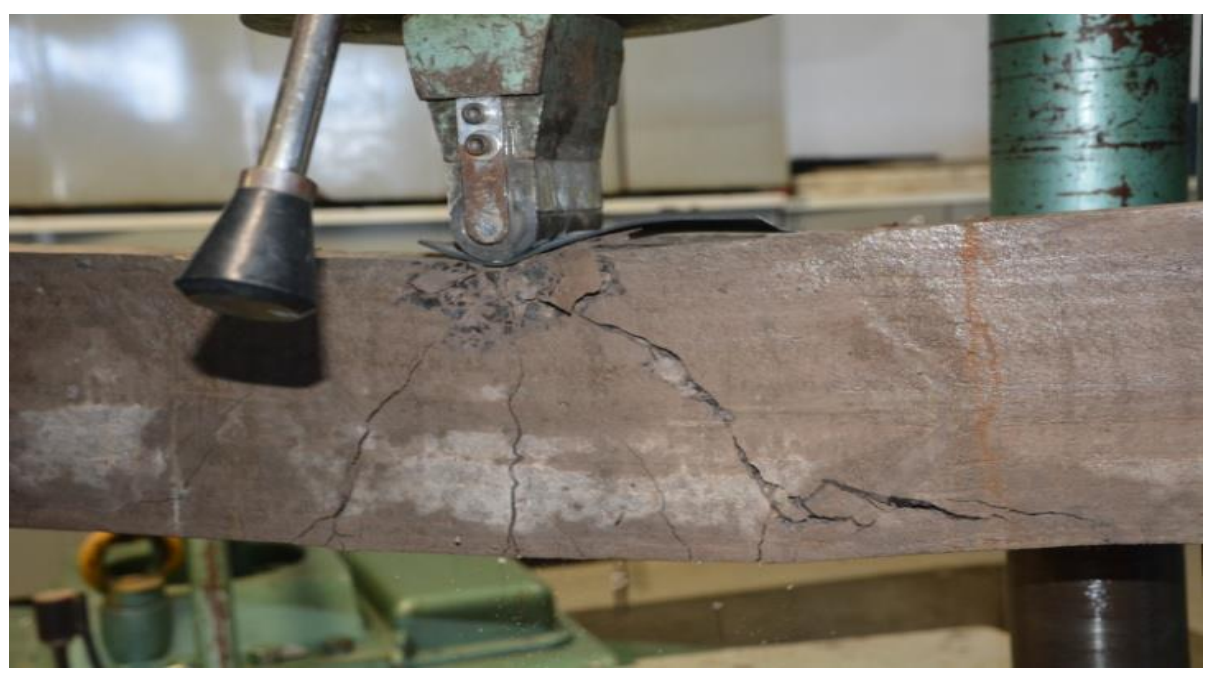

Figura 5: Ruptura por esmagamento do concreto na viga reforçada com aço 
A primeira viga reforçada com fibra de basalto apresentou uma ruptura típica por cisalhamento (Figura 6). Na segunda viga observou-se a ruptura da barra longitudinal em fibra de basalto na região junto ao estribo (Figura 7). A ruptura da barra inferior foi possivelmente causada por danos durante a montagem do reforço.

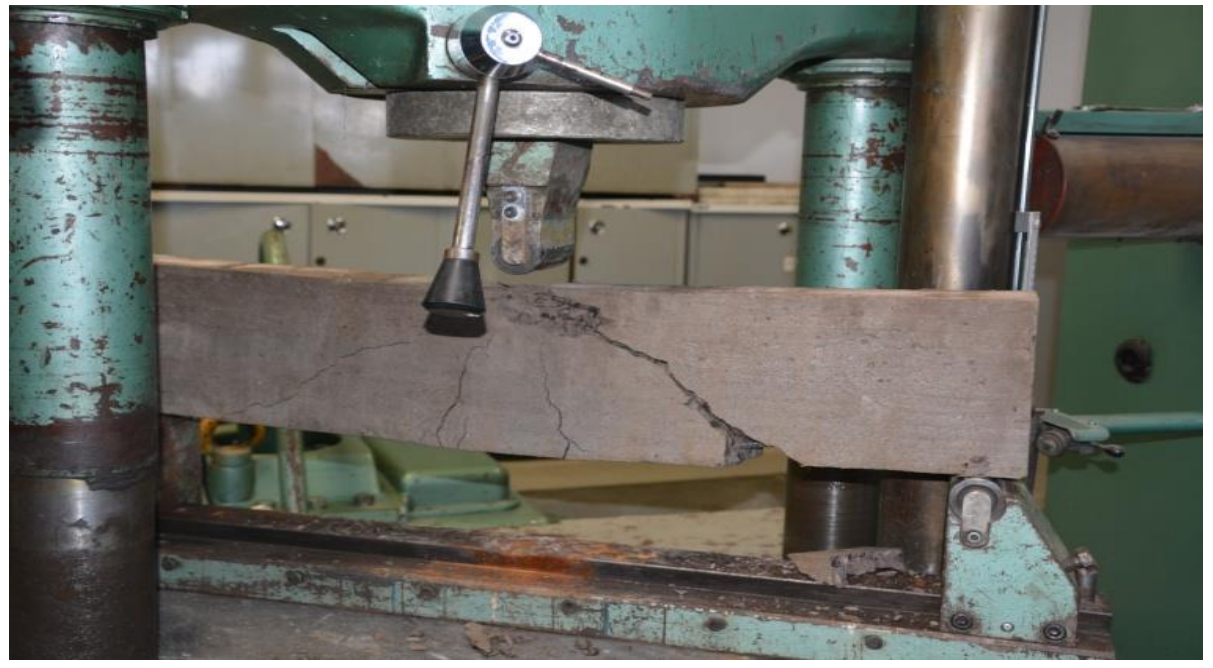

Figura 6: Ruptura por cisalhamento da viga reforçada com barra em fibra de basalto

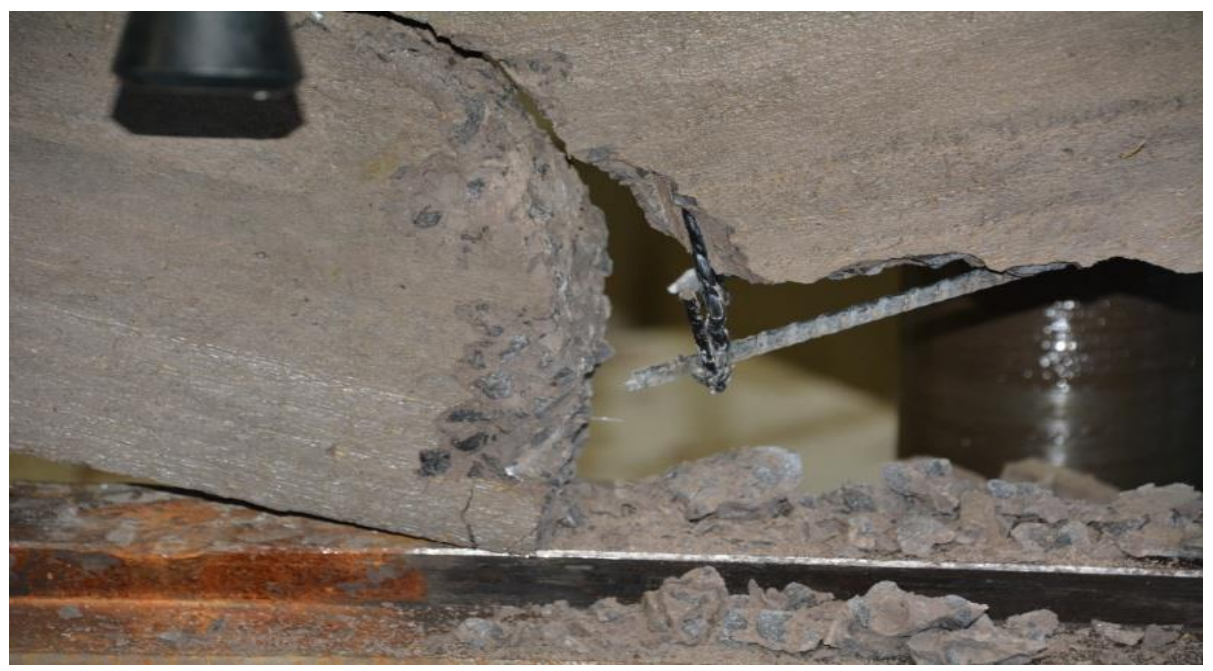

Figura 7: Ruptura da barra em fibra de basalto

\subsection{Relação carga - deflexão}

A Figura 8 mostra a relação carga - deflexão para as vigas reforçadas com barras de aço, e a Figura 9 para as vigas reforçadas com barras em fibra de basalto. A Figura 10 mostra o comparativo entre as vigas reforçadas com barras de aço e com barras em fibra de basalto.

É possível observar que as as vigas de aço apresentaram um patamar, onde a carga permanece constante e as deformações aumentam consideravelmente. O patamar ocorre quando 0 aço atinge a tensão de escoamento, caracterizando um comportamento dúctil. 
BALDESSAR, G.M.W.; SANTOS FILHO, M.L.; DALLEDONE, R.M.; PIERALISI, R., COMPORTAMENTO DE VIGAS REFORÇADAS COM AÇO E COM BARRAS DE FIBRA DE BASALTO. $4^{\circ}$ Simpósio Paranaense de Patologia das Construções (40 SPPC), artigo 4SPPC133, pp. 312 - 320, 2019. DOI: 10.4322/2526-7248.053

As vigas reforçadas com barras em fibra de basalto, por sua vez, apresentaram uma relação carga - deflexão curva e sem patamar de escoamento. A ausência do patamar de escoamento é decorrente da relação linear entre tensão e deformação do material de reforço.

Quando se compara os dois gráficos, é possível observar que a viga reforçada com barras em fibra de basalto apresenta maiores deflexões para uma mesma carga, esse comportamento ocorre pois o módulo de elasticidade da fibra de basalto é menor que o do aço.

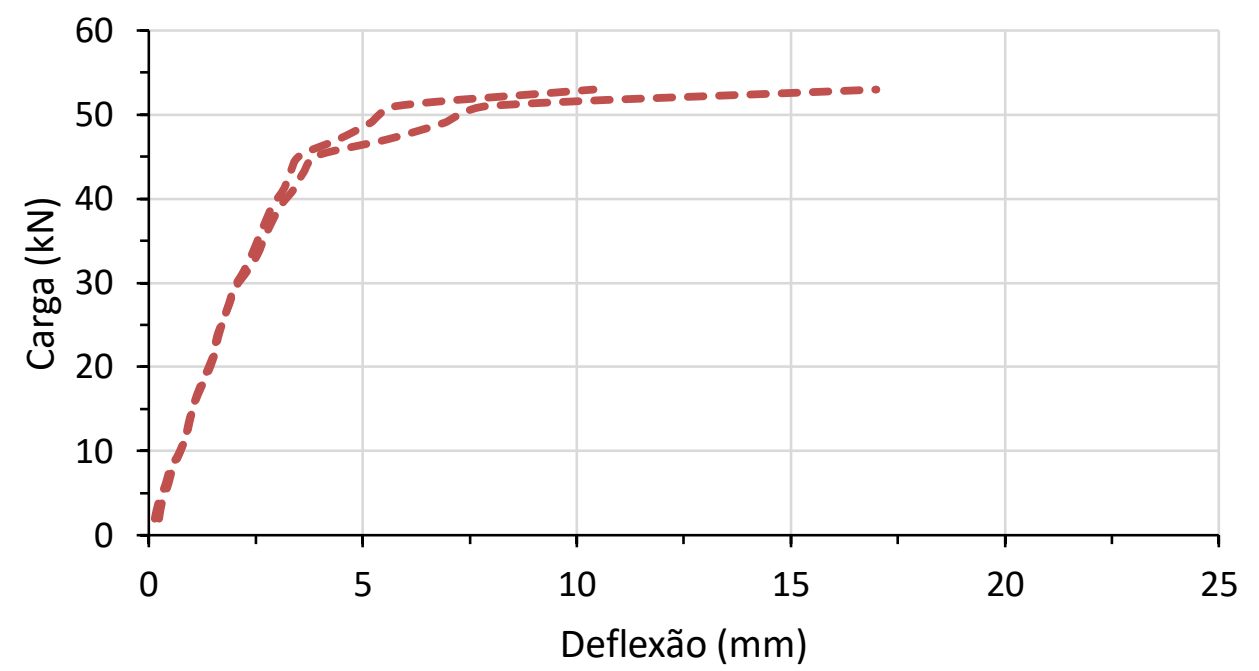

Figura 8: Gráfico carga - deflexão para a viga reforçada com barras de aço

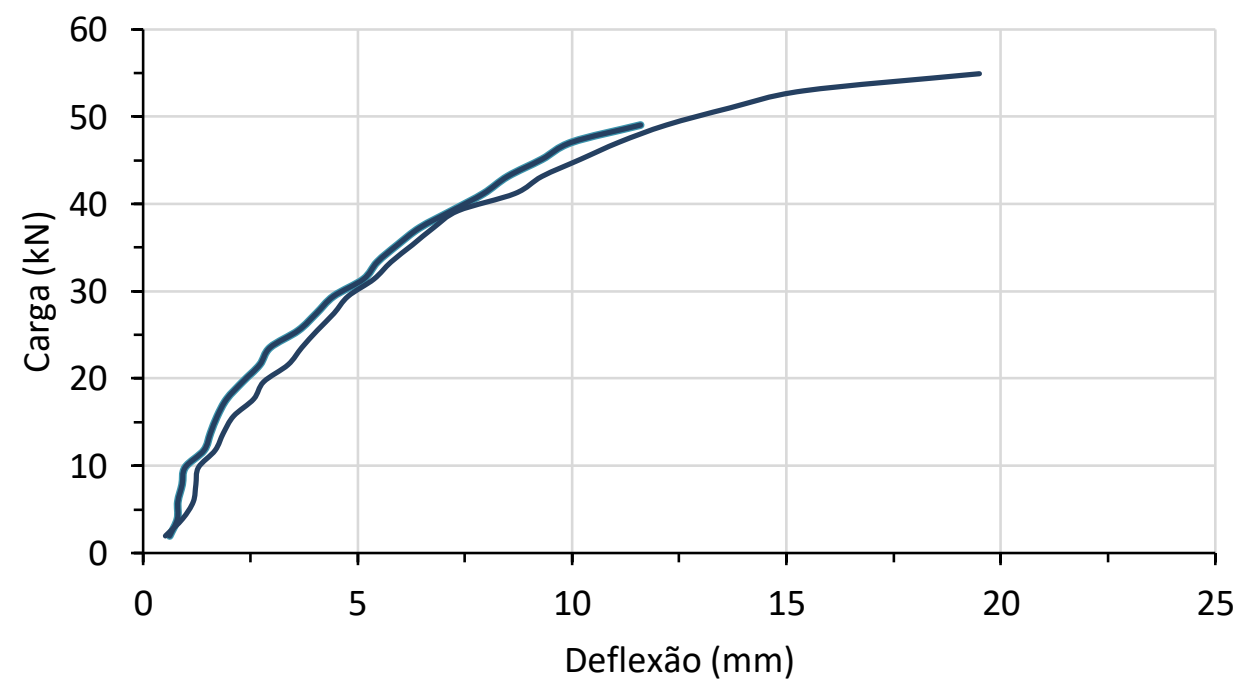

Figura 9: Relação carga - deflexão para as vigas reforçadas com barras em fibra de basalto 


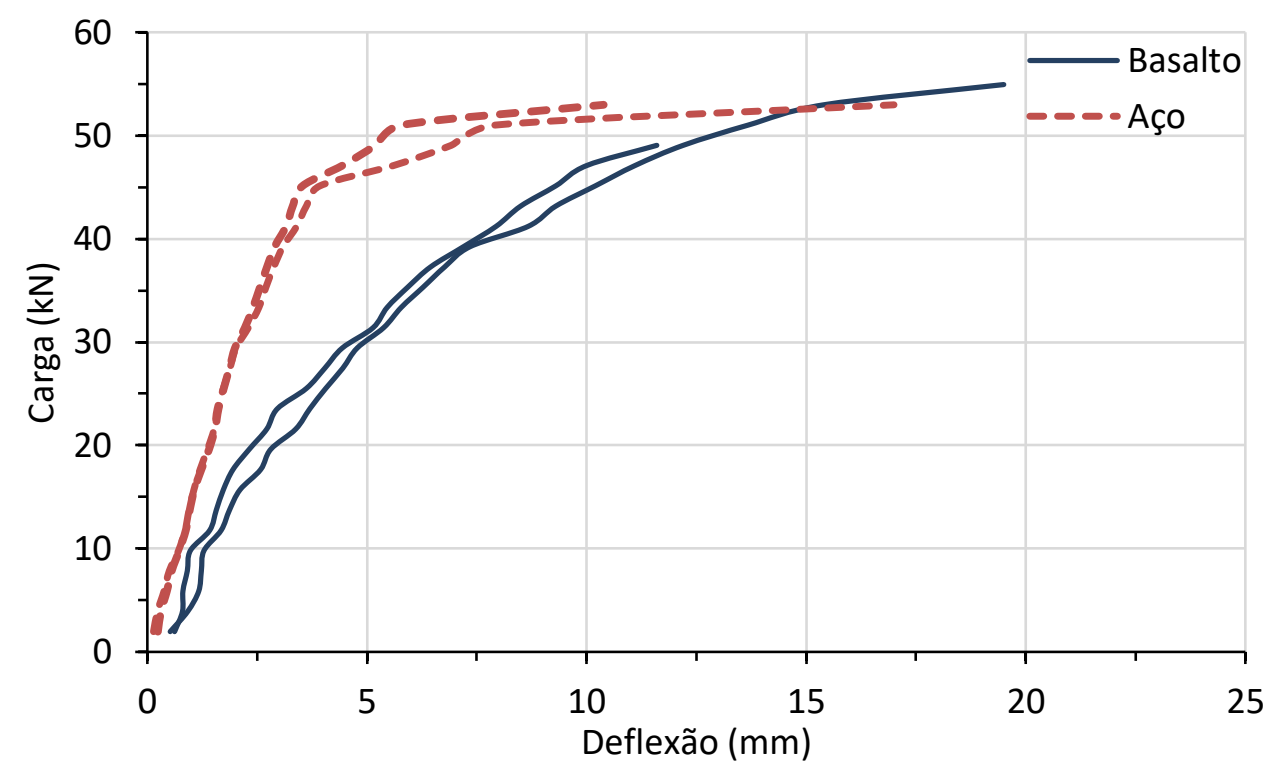

Figura 10: Comparativo entre as vigas reforçadas com barras de aço e com fibra de basalto

\section{Conclusão}

Devido à geometria da viga utilizada no ensaio, com relação altura/comprimento de 0,2 , houve um efeito mais rigoroso do esforço de cisalhamento, incorrendo numa maior tensão de compressão nas bielas comprimidas do concreto. Essa configuração ocasionou a ruptura do estribo na viga reforçada com barras de aço.

Diferentemente do esperado, as vigas reforçadas com barras em fibra de basalto apresentaram uma relação carga - deformação curva. Isso não seria esperado pois o material apresenta comportamento elástico-linear até a ruptura. Tal comportamento deve-se à configuração do ensaio, com preponderancia dos esforços de cisalhamento e também devido ao possível escorregamento da barra, uma vez que com uma viga muito curta não se desenvolve o comprimento de ancoragem adequado.

Outro fator evidenciado é a sensibilidade das barras de fibra de basalto durante a montagem. Deve-se ter cuidado nessa fase para que a estrutura apresente um comportamento adequado.

O comportamento dos dois tipos de vigas foi similar, dadas as características dos ensaios realizados. Naquilo que foi executado, percebeu-se que os compósitos em fibra de basalto tiveram um comportamento similar à armadura convencional. As cargas últimas ficaram muito próximas. Isso se deve, sobretudo, ao modo de ruptura na biela comprimida do concreto. Como o concreto das vigas apresentavam a mesma resistência, esperava-se uma carga última similar.

Conclui-se que as vigas reforçadas com barras em fibra de basalto podem ser usadas em reforços de vigas, sobretudo em ambientes agressivos. Contudo a simples substituição de um material pelo outro, mantendo-se a bitola, não é adequado. Devem ser consideradas no cálculo as características de ruptura frágil do material e a alta deflexão decorrente do baixo módulo de elasticidade. 


\section{Referências}

[1] Kobayashi, K.; lizuca, T.; Kurachi, H.; Rokugo, K. (2010) Corrosion protection performance of High Performance Fiber Reinforced Cement Composites as a repair material, Cement and Concrete Composites, 32:411-420.

[2] Kobayashi, K.; Rokugo, K. (2013) Mechanical performance of corroded RC member repaired by HPFRCC patching, Construction and Building Materials, 39:139-147.

[3] The High Cost of Corrosion (2019), Focus on Powder Coatings, 5:1-1.

[4] Guo, F.; Al-Saadi, S.; Singh Raman, R.K.; Zhao, X.L. (2018) Durability of fiber reinforced polymer (FRP) in simulated seawater sea sand concrete (SWSCC) environment, Corrosion Science, 141:1-13.

[5] Attia, K.; Alnahhal, W.; Elrefai, A.; Rihan, Y. (2019) Flexural behavior of basalt fiber-reinforced concrete slab atrips reinforced with BFRP and GFRP, Composite Structures, 211:1-12.

[6] Pawlowski, D.; Szumigala, M. (2015) Flexural behaviour of full-scale basalt FRP RC beams - experimental and numerical studies, Procedia Engineering, 108:518525.

[7] Monaldo, E.; Nerilli, F.; Vairo, G. (2019) Basalt-fiber reinforced materials and structural applications in civil engineering, Composite Structures, 214:246-263.

[8] Jumaa, G. B.; Yousif, A. R. (2019) Size effect on the shear failure of high-strength concrete beams reinforced with basalt FRP bars and stirrups, Construction and Building Materials, 209:77-94.

[9] Elgabbas, F.; Vincent, P.; Ahmed, E.A.; Benmokrane, B. (2016) Experimental testing of basalt-fiber-reinforced polymer in concrete beams, Composites Part $B$ : Engineering, 91:205-218. 